\title{
Educação ao ar livre pela aventura: o aprendizado de va- lores morais em expedições à natureza
}

Flavio Theodor Kunreuther

Osvaldo Luiz Ferraz

Universidade de São Paulo

Correspondência:

Flavio Theodor Kunreuther

Universidade de São Paulo

Escola de Educação Física e Esporte

Av. Prof. Melo Moraes, 65

Cidade Universitária

05508-030 - São Paulo/SP

flatku@yahoo.com.br

\section{Resumo}

A educação ao ar livre, por meio de cursos no formato expedição, ainda acontece de forma tímida no Brasil. Entende-se por expedição uma experiência educacional contínua, de múltiplos dias, em que alunos e instrutores aventuram-se em um trajeto em área remota da natureza de forma autossuficiente. 0 presente estudo analisa os cursos desse tipo. Por meio de entrevistas e questionários semiestruturados, investigou-se a aprendizagem dos alunos segundo suas próprias percepções e as dos educadores da instituição, com ênfase no desenvolvimento moral do indivíduo. Como parte do estudo de caso sobre um aluno adolescente participante de um dos cursos, entrevistou-se também uma psicóloga que coordena um abrigo para menores. Os resultados encontrados indicam que os cursos de educação ao ar livre caracterizam-se por experiências que estimulam trabalhos em grupo, debates sobre justiça e solidariedade, e reflexões sobre valores e princípios como coragem, esforço pessoal, disciplina, respeito e superação de limites. Os resultados também indicam que tal proposta educacional aufere experiências sensíveis e de conexão do ser humano com a natureza. Muito embora haja potencial educacional para a educação ao ar livre, a atuação do educador perante seus alunos é fundamental para que as experiências sejam física e psicologicamente seguras, alcancem seus potenciais pedagógicos de desenvolvimento da moralidade e ajudem as pessoas a desenvolverem uma consciência ambiental, manifestada por meio de ações concretas ao retornarem dos cursos para suas comunidades.

\section{Palavras-chave}

Educação - Aventura - Desenvolvimento moral. 


\section{Education outdoors through adventure: learning moral va- lues in nature expeditions}

Flavio Theodor Kunreuther

Osvaldo Luiz Ferraz

University of São Paulo

\begin{abstract}
Open air education through courses organized as expeditions is still incipient in Brazil. We understand an expedition as a continued educational experience taking several days in which students and instructors venture into a remote natural area in a self-sufficient way. The present study analyzes courses of this type. Using interviews and semi-structured questionnaires, it investigates student's learning according to their own perceptions and to those of the educators, with an emphasis on the moral development of the individual. As part of the case study with a teenage student who took part in one of the courses, a psychologist who coordinates a shelter for minors was also interviewed. The results indicate that open air education courses are characterized by experiences that stimulate teamwork, debates about justice and solidarity, and reflections about values and principles such as courage, personal effort, discipline, respect, and the overcoming of limits. The results also indicate that this educational proposal yields experiences of the senses and of connection with nature. Although there is an educational potential for education outdoors, the action of the educator with the students is fundamental to produce physically and psychologically safe experiences that reach their pedagogical potential for the development of morality, and help people to develop environmental awareness manifested through the concrete actions of those who return from the courses to their communities of origin.
\end{abstract}

\section{Keywords}

Education - Adventure - Moral development.

\footnotetext{
Contact:

Flavio Theodor Kunreuther Universidade de São Paulo Escola de Educação Física e Esporte Av. Prof. Melo Moraes, 65 05508-030 - São Paulo/SP flatku@yahoo.com.br
} 
A educação ao ar livre, por meio de cursos no formato expedição, ainda acontece de forma tímida no Brasil. Entende-se por expedição uma experiência educacional contínua, de múltiplos dias, em que alunos e instrutores percorrem um trajeto em área remota na natureza de forma autossuficiente, ou seja, munidos de todo o equipamento e de toda a comida de que necessitam.

Tanto na língua inglesa como em português, há mais de um termo para designar esse tipo de educação. Neste artigo, utilizaremos o termo educação ao ar livre, mas tendo sempre em mente que, não obstante haja diferentes formas de educação experiencial, o objeto de nosso estudo é a educação ao ar livre no formato expedição em áreas naturais remotas.

Em países como Inglaterra, Canadá, Austrália e Estados Unidos, a outdoor education é bastante utilizada como recurso pedagógico, principalmente por meio do montanhismo e da canoagem, mas também de cavalgadas, esqui na neve, trenós puxados por cães, iatismo e outras modalidades de deslocamento pela natureza. Nesses países, há extensa bibliografia sobre os processos educacionais e os resultados de aprendizagem nesses cursos.

Como cada escola de educação ao ar livre tem características próprias, não há garantias de que os resultados das pesquisas aplicadas em outras realidades e localidades estendam-se ao caso brasileiro. Além disso, o estudo de tal proposta educacional trata de um aspecto fundamental à educação contemporânea: o desenvolvimento moral do ser humano.

Ressaltamos, contudo, que a proposta educacional dos cursos no formato expedição funda-se na combinação da possibilidade de desenvolvimento moral a partir de experiências intensas e desafiadoras com o fato de essas experiências ocorrerem em áreas naturais. Considerando-se que vivemos em uma sociedade tão urbanizada, distante de áreas naturais e que, cada vez mais, discute questões ambientais, como desmatamento, biodiversidade, alterações climáticas, crescimento econômico sustentável, entre outras, e questões sociais, como violência, ética e estresse, interessamo-nos em estudar se a possibilidade de reaproximação com a natureza apresenta potencial para preparar melhor o ser humano para os desafios da vida.

\section{Ética e a educação ao ar livre}

Moral e ética, salvo convenção específica, são termos sinônimos. Ocorre que diferentes áreas do conhecimento humano e diferentes autores convencionaram atribuir-lhes significados distintos. Para alguns, a moral é do âmbito privado e a ética, do âmbito público; para outros, a moral é o conjunto de regras, princípios e deveres que orientam a vida de uma pessoa em sociedade, e a ética é o estudo dessa moral; há os que defendem que a moral trata da relação do homem com as regras e os deveres, e que a ética é sua relação com a vida que almeja para si. Para efeito deste texto, consideraremos ambas como sinônimas e aceitaremos a definição de moral como o conjunto de princípios, crenças e regras que orientam o comportamento do indivíduo nas diversas sociedades (BRASIL, 1998).

Se aceitarmos tal definição, fica evidente que a moralidade trata da forma como as pessoas se relacionam; o que é aceitável e o que não se tolera no convívio social. Assim, surge o debate se a ética é uma imposição social - e, portanto, heterônoma para o indivíduo - ou se uma pessoa pode ser autônoma em seu julgamento moral. Grandes pensadores discorreram e divergiram sobre esse tema.

As virtudes apregoadas por Platão - sabedoria, temperança, coragem e justiça - não eram vistas como imposições ou prescrições sociais, mas como a busca da potencialidade e da harmonia de cada pessoa - o conceito de aretê. Então, seria a moralidade dever, obrigação, ou querer, aspiração? As tais regras sociais que orientam o comportamento do indivíduo não seriam uma imposição?

Na resposta a essa questão, encontraremos também a luz para muitos dos problemas que envolvem a ética. A moralidade é expressão 
do dever e do querer. Yves de La Taille (2006) ensina-nos que o gozo da felicidade - ou, mais tecnicamente, a expansão de si próprio - só é possível àqueles que se percebem como uma pessoa de valor. Para perceber-se como valorosa, faz-se necessário que tal pessoa legitime um código de condutas e aja de acordo com ele. 0 agir de acordo com esse código nasce da sensação de obrigatoriedade, obrigação que só existe porque a pessoa quer ser vista e ver-se como valorosa. 0 autorrespeito - que é a valorização de si próprio quando questões morais estão envolvidas - é o elo de ligação entre a expansão de si próprio com a sensação de obrigatoriedade, ou seja, o elo do querer com o dever.

Dentre os poucos autores que tratam da moralidade na educação ao ar livre, Daniel Garvey (1999) afırma que, para que se possa ampliar o grande potencial de desenvolvimento moral por meio de programas de educação pela aventura, primeiro deve-se elevar o desenvolvimento moral a um dos objetivos principais desse modelo educacional. Na falta de mais estudos que comprovem ou refutem a proposta educacional pela aventura como capaz de desenvolver a moralidade de seus alunos, seguiremos um pouco mais pelo caminho teórico, utilizando-nos de autores que estudaram o tema.

Começamos com Jean Piaget (1994), para quem o juízo moral é fruto da razão e é possivel ao ser humano atingir autonomia em seus julgamentos morais, tendo passado por um processo de desenvolvimento que se inicia na anomia, passa pela heteronomia e - potencialmente, mas não necessariamente - chega à autonomia. Não significa que um homem seja totalmente autônomo em qualquer circunstância de sua vida. Ninguém o é. Contudo, existe a possibilidade de que a autonomia seja alcançada por meio de um histórico de desenvolvimento biológico, combinado com as experiências de vida e os ensinamentos formais, em um processo que Piaget denominou de equilibração. Esta só é possível porque o homem dispõe da capacidade de autorregulação, que lhe permite or- ganizar as experiências e os conhecimentos adquiridos em sua estrutura de inteligência.

A combinação de desenvolvimento biológico com as experiências de vida e os ensinamentos formais levará o indivíduo da anomia para a heteronomia moral e, possivelmente, para a autonomia. Portanto, a capacidade de um sujeito de avaliar uma regra moral imposta pela figura de autoridade ou pela sociedade, validando-a ou não, irá depender das interações sociais que ele venha a ter. Se estas forem baseadas na coerção, tende-se a estimular o desenvolvimento de sujeitos moralmente heterônomos, que pouco irão além de validar as imposições da autoridade ou da sociedade. Em contrapartida, se tais relações forem baseadas na reciprocidade e na equidade entre as partes, existe potencial para o desenvolvimento de sujeitos autônomos.

Tal discurso sobre educação remete-nos a John Dewey, para quem a educação democrática e a liberdade são meios para que os alunos entendam seus direitos e responsabilidades a fim de agirem de forma ética (GARVEY, 1999). Aqui parece que encontramos a correlação teórica entre as proposições de Dewey (1979) e Piaget (1998), e entre o valor da experiência argumentada pelo primeiro e a possibilidade de desenvolvimento moral defendida pelo segundo.

Lawrence Kohlberg, um dos seguidores teóricos de Piaget, estendeu os estudos deste sobre a moralidade. Ele não somente ratificou a racionalidade do julgamento moral, a justiça como o grande valor da moralidade e a perspectiva de autonomia sugeridas por Piaget, como elaborou seis estágios de desenvolvimento moral. Contudo, suas pesquisas mostraram que o reconhecimento de tais estágios de moralidade não garante que os níveis mais altos sejam comumente encontrados nas pessoas. Trata-se, antes, de um potencial, mas não de uma certeza (MENIN, 1996).

Kohlberg criou propostas para o estímulo do desenvolvimento moral dos jovens por meio de dilemas: inicialmente, dilemas morais conceituais; posteriormente, dilemas práticos 
advindos da realidade do dia a dia dos alunos das escolas em que implementou sua proposta, à qual chamou de modelo just-community.

Garvey (1999), a respeito do conceito de just-community aplicado às atividades de aventura ao ar livre, afirma que os valores e normas necessários aos grupos, visando à segurança e à eficiência nas atividades outdoor, têm grande potencial para reproduzirem tal proposta. Os cursos iniciam-se com os membros de uma expedição debatendo as regras que permearão toda a experiência e o convívio entre as pessoas. Ainda assim, ao longo dos cursos, muitas situações de conflitos, interesses divergentes e dilemas morais ocorrem. Quase todos os dias encerram-se com as pessoas discutindo as experiências vividas, os momentos de êxito e de frustração e os problemas que ocorreram. É nesse fórum que muitas questões são tratadas e que acordos são lembrados e reformulados.

Para a educação moral, o dilema que importa não é o da resposta óbvia, mas o da decisão sobre o que é certo, principalmente quando o certo não é evidente e não há uma única opção. Pelo contrário, o dilema moral verdadeiro está na decisão sobre diferentes argumentos baseados na interpretação do que é legítimo. Tais argumentos e suas interpretações têm especial relevância quando consideramos o contexto da aventura, em que há riscos envolvidos para os participantes, riscos estes que são percebidos de forma diferente por cada pessoa. A solução razoável para alguns pode ser arriscada e inaceitável para outros. Assim, para o entendimento da dimensão dos potenciais dilemas e questões morais dessa proposta educacional, torna-se fundamental a compreensão dos conceitos de aventura, natureza, educação e risco.

\section{Aventura, educação, natureza e risco}

Uma experiência educacional pode ser uma aventura urbana e não na natureza; da mesma forma, uma experiência pode ocorrer na natureza e não ser uma aventura. É na combinação dos elementos natureza e aventura que algumas escolas de educação experiencial desenvolvem seu trabalho. Com Phyllis Ford (1981), aceitamos a definição da educação ao ar livre como a educação na, sobre e para as áreas naturais.

Andrew Martin (2001), em sua compreensão de educação pela aventura, identifica elementos de perigo real ou aparente cujos resultados, ainda que incertos, podem ser influenciados pelas ações dos participantes. Alcyane Marinho (2008), em sua abordagem do lazer para a aventura, além do risco, do imprevisto e da incerteza, relaciona a busca por situações novas, desafiadoras e transmissoras de conhecimentos.

Encontramos aqui uma situação paradoxal. Por que o ser humano, tão cioso por segurança e estabilidade, ao conseguir assegurar um ponto de desenvolvimento no qual alguns riscos do passado estão afastados, passa a buscar e a criar para si situações de aventura ou de risco? A esse respeito, citamos Jeff Liddle (1998):

Um paradoxo do nosso tempo é que, como sociedade, buscamos segurança a quase qualquer custo, no entanto, esta mesma segurança alimenta uma complacência que parece, por fim, erodir nosso espírito. Nunca render-se totalmente a esta complacência é crítico à condição humana. Encontrar um porto em uma tormenta é sempre um conforto, assim como uma sopa quente em um dia frio e chuvoso o é, mas uma vida passada somente no porto é uma história de oportunidades perdidas. A luta significativa pela existência está profundamente arraigada em nossa psique e, quanto mais seguro e confortável se torne o nosso mundo, tanto mais necessária se torna a educação pela aventura. (p. 61)

Segundo David Le Breton (2009), uma parte dos aventureiros, especialmente os jovens, é movida pela busca por legitimação e, portanto, por autorrespeito. Trata-se, então, de enfrentar o risco para reconhecer-se como uma pessoa de valor; não para morrer, mas, ao contrário, 
para justificar a existência. Nesse contexto, o ser humano elege a natureza como palco de sua provação, pois ela representa muito bem o obstáculo, o ambiente da superação, e certifica o ser humano de sua existência, revelando seus recursos físicos e morais. É interessante observar como essa análise de Le Breton é carregada de valores morais - justiça, coragem, prudência.

Assim como a definição de aventura alterou-se ao longo da história, o mesmo ocorreu com a compreensão sobre a natureza, conforme alerta Heloisa Turini Bruhns (2000). De tudo o que existe, seu significado restringiu-se a campo, cenário, selvagem. Ao limitá-la, o ser humano também a vestiu com trajes de produto. Esse empobrecimento, em vez de corrigir a dissociação entre cidade e natureza, mantém-na, limitando as possibilidades de transferências holísticas de aprendizados. Parece-nos, então, que a experiência vivida na mata ou nas montanhas deixa de ter relação com a realidade urbana. Perde-se a possibilidade de conexão profunda e sensível com o mundo natural, que é o ambiente externo e o próprio eu.

0 ambientalismo, contudo, apresenta o argumento para a educação por meio da aventura na, pela e para a natureza, pois faz da preservação do meio natural uma de suas metas e traz a discussão sobre valores e ética na relação dos seres humanos entre si e também com a natureza, por meio de reflexões sobre os impactos ambientais da ação humana. Sendo assim, justifica-se analisar as potenciais contribuições da educação que se utiliza da aventura e da natureza para o desenvolvimento moral dos seres humanos, em suas relações entre si e com o mundo que os cerca.

Nesse sentido, a pesquisa que embasa as reflexões aqui expostas teve por objetivo analisar a percepção de alunos adolescentes, alunos adultos e educadores da instituição sobre aprendizados éticos decorrentes de um curso de educação ao ar livre. Objetivou-se, ainda, examinar as decorrências de um curso de educação ao ar livre em um adolescente advindo de abrigo para menores, sob o ponto de vista da coordenadora e psicóloga desse abrigo.
A pesquisa apresenta quatro estudos. No primeiro deles, por identificarmos a dificuldade de expressão dos jovens por meio da escrita, optamos pela entrevista individual (gravada e transcrita) com alunos entre 14 e 18 anos, integrantes de um curso com duração de dez dias. As entrevistas semiestruturadas abordaram as seguintes questões: o que você mais gostou em seu curso? 0 que você menos gostou em seu curso? 0 que você aprendeu com o curso? Por que esse aprendizado é importante? Como você usa esse aprendizado em sua vida? Em que outros lugares ou situações você também aprende essas coisas? 0 que foi difícil para você durante o curso? Como se tratou de uma entrevista semiestruturada, em alguns casos, o entrevistador solicitou explicações ou exemplos.

Para o segundo estudo, optamos por questionário enviado por e-mail a alunos adultos do curso para educadores, com duração aproximada de duas semanas. As perguntas nele incluídas foram: você poderia discorrer sobre situações de conflito ou desentendimento entre os participantes de seu curso e sobre como elas foram resolvidas? Em todos os cursos, as pessoas apresentam diferentes competências e limitações; você poderia relatar como o grupo se organizou para considerá-las e resolvê-las? Que valores educacionais você vê em um curso como esse? 0 que mais você aprendeu com o curso? Quais atividades lhe proporcionaram maior aprendizado? Em quais momentos você se sentiu mais desafiado? Por quê?

No terceiro estudo, também elaborado a partir de questionário, os sujeitos priorizados foram instrutores da instituição que já tinham efetivamente trabalhado em campo. 0 questionário continha as seguintes perguntas: o que você acha que os alunos mais aprendem nos cursos em formato expedição? Você poderia discorrer e dar exemplos sobre situações de conflito ou desentendimento entre os participantes de cursos e sobre como elas foram resolvidas? Em todos os cursos, as pessoas apresentam diferentes competências e limitações; você poderia relatar como os grupos se 
organizam para considerá-las e resolvê-las? A instituição tem como missão ajudar as pessoas a descobrirem e desenvolverem o seu potencial para cuidar de si próprias, de outros e do mundo à sua volta, através de experiências desafiadoras em locais não familiares; você acredita que a escola consegue realizar sua missão por meio de cursos em formato expedição? Por quê? Você poderia citar exemplos? Você acredita que adolescentes e adultos aprendem as mesmas coisas nos cursos ou têm aprendizados diferentes? Por favor, explique.

0 quarto estudo consistiu-se de entrevista aberta para colher os relatos da coordenadora e psicóloga do abrigo para menores que enviou o aluno (designado A4) ao curso de educação ao ar livre. A pergunta inicial era: o que vocês sentiram de diferença no aluno A4? 0 diálogo foi gravado e transcrito, e as respostas foram categorizadas de acordo com a técnica de análise de conteúdo (TRIVIÑOS, 1987), seguindo-se as etapas por ela propostas.

\section{Das limitações deste trabalho}

Não há uma prova que meça, de forma objetiva, os aprendizados ou alterações de comportamento dos alunos de educação ao ar livre. Trata-se da percepção dos próprios sujeitos e dos educadores envolvidos. Com exceção de um estudo de caso que relata as observações da coordenadora e psicóloga de um abrigo para menores, apresentando, portanto, a visão de alguém não diretamente envolvido na intervenção pedagógica, não há comprovação de que os aprendizados relatados pelos alunos de fato ocorreram, ou de que foram transformados em alterações comportamentais.

0 desenvolvimento da capacidade de julgamento moral não necessariamente se transforma em ação. Um estudo do tipo observação participante seria um interessante próximo passo para avaliar as diferenças entre o discurso e a ação dos alunos.

Possivelmente, apenas respondeu ao questionário da pesquisa aqueles que acharam a experiência significativa ou válida. Se assim for, não temos acesso à opinião de quem não reconheceu aprendizados significativos. Além disso, a pesquisa entrevistou ou questionou um número reduzido de sujeitos, e, devido a isso, alertamos para a necessidade de estudos posteriores. Por ora, buscamos indicadores da potencialidade da proposta educacional em questão.

\section{Sobre os sujeitos}

Para simplificar a identificação dos sujeitos e manter sigilo em relação às suas identidades, todos são aqui referidos por códigos: a representação dos alunos adolescentes é precedida pela letra A; a dos alunos adultos, pela letra F; a dos educadores da instituição, pela letra I. À letra indicativa do tipo de sujeito, segue o número da ordem das entrevistas aplicadas ou do recebimento de questionários.

Os alunos adolescentes, no total de nove e com idade entre 14 e 18 anos, eram todos de um mesmo curso com duração de dez dias, no Parque Estadual de Campos do Jordão. Eles haviam ido a campo com dois educadores e foram entrevistados no último dia do curso. Dentre esses jovens, havia um aluno advindo de um abrigo para menores - o sujeito A4 -, cujas alterações comportamentais e sua análise estão comentadas em um estudo de caso específico.

Os alunos adultos que participaram da pesquisa são todos ex-participantes do curso para educadores. Foram enviados, por e-mail, questionários a 64 ex-alunos, dos quais dezessete responderam. Tais respostas representam alunos de sete diferentes cursos, ocorridos entre 2007 e 2010.

Aos educadores da instituição - que também chamamos de instrutores - foram enviados 25 questionários, dos quais doze foram respondidos. Todos os profissionais que responderam já atuaram em cursos com adolescentes e adultos, sendo que cinco deles possuem experiência internacional, de capacitação ou atuação, em países como México, Estados Unidos e Canadá.

A análise do material arrolado indica uma série de características da educação ao ar livre e 
do aprendizado de valores morais em expedições dessa natureza, tal como será abordado a seguir.

\section{Trabalho em grupo}

A cooperação entre os alunos de um curso por meio de uma aventura de múltiplos dias na natureza foi assunto recorrente nas respostas das entrevistas e dos questionários aplicados aos sujeitos deste estudo.

$\mathrm{Na}$ análise das respostas dos alunos adolescentes, chama a atenção o fato de todos eles relacionarem o trabalho em grupo como um aprendizado do curso. Na maioria dos casos, a expressão utilizada foi trabalho em grupo ou trabalhar em grupo. Também foram utilizadas as expressões trabalhar junto e lidar com o grupo, dividir as coisas, não pensar só em mim.

Para a compreensão da importância do trabalho em grupo no desenvolvimento da razão e da moralidade, é fundamental o entendimento de três aspectos. 0 primeiro é que o indivíduo só se conhece por meio da relação com o outro. 0 segundo aspecto é que a cooperação é fundamental para levar a criança à objetividade, pois é na relação com o outro que ela percebe que, além de sua perspectiva particular, há a perspectiva do outro. A cooperação requer a coordenação de perspectivas, o que só ocorre com a objetividade. 0 terceiro aspecto necessário à compreensão da importância do trabalho em grupo é que a cooperação fornece regras para o pensamento, as quais determinam as ações não contraditórias de um indivíduo. É no relacionamento com outros que uma pessoa vê-se obrigada a ser coerente em seu discurso.

Piaget (1998) assevera:

É desnecessário sublinhar, por fim, o paralelo que nossos colaboradores estabelecem entre esses resultados de ordem intelectual e os resultados obtidos no domínio da educação moral: a iniciativa e a disciplina, o esforço pessoal e a ajuda recíproca são os dois pólos tanto da ação moral como do verdadeiro pensamento, pois os mesmos processos engendram os mesmos efeitos em ambos os casos. (p. 151)

Podemos afirmar que o curso proveu múltiplas oportunidades de trabalhos em grupo ou ajuda recíproca, com potencial para o desenvolvimento moral dos alunos. Dentre os alunos adultos, nove dos dezessete pesquisados relataram a cooperação como relevante em suas avaliações sobre a experiência do curso. Foram utilizadas expressões como trabalho em grupo, trabalho em equipe, trabalho em conjunto, atividades comunitárias, divisão das tarefas para cuidar do grupo, e perceber, participando do curso, o quanto o grupo realmente tem força e possibilidades.

A percepção do trabalho em grupo como um dos elementos dos cursos também está presente dentre os instrutores, sendo que seis das doze respostas recebidas tratam direta e especificamente da cooperação, por meio de expressões como trabalho em equipe, senso de cooperatividade, trabalho em grupo e colaboração do grupo.

\section{Iniciativa}

No excerto de Piaget aqui mencionado sobre o que ele definiu como polos da ação moral e do pensamento, concordamos com a importância da iniciativa, da disciplina e do esforço pessoal, além da ajuda recíproca, que já analisamos.

Ao referir-se à iniciativa, cremos que Piaget trata da ação que se segue à percepção de uma necessidade ou a um julgamento. Um dos desafios dos estudiosos da moralidade e também dos educadores é a transformação do julgamento em ação efetiva. Assim, não basta o pensar ou o julgar corretos se estes não são seguidos de ação.

Na educação pela experiência, a iniciativa faz-se premente. A percepção de que a mochila de um colega está desproporcionalmente pesada, ou de que apenas uma parte das pessoas 
esforça-se em montar barracas ou lavar a louça - exemplos citados na pesquisa - e isso não está correto, se não for seguida de alguma iniciativa para a resolução do problema, não terá servido para nada, podendo até ser entendida como omissão. É na experiência concreta e no dilema real, e não na teorização, que a ação tem de fato a oportunidade de suceder o julgamento.

\section{Disciplina, esforço, superação e coragem}

Também colhemos, entre os sujeitos do estudo, relatos que remetem à virtude da coragem e à superação de desafios, além da disciplina e do esforço pessoal, importantes no desenvolvimento da razão e da moral (PIAGET, 1998). Os alunos fizeram referências como: "bom, eu consegui fazer algumas metáforas, por exemplo, do não desistir. Quando eu crescer, for fazer alguma coisa que eu queira, não desistir" (A7); "estar conhecendo um ambiente fora da minha área de conforto" (A1).

Também entre os alunos adultos, encontramos menções em relação às questões de superação, esforço pessoal, disciplina e coragem, como na seguinte declaração de F4: "aprendi muito mais sobre os meus limites, não apenas sobre os limites físicos, mas os limites da tolerância e do autocontrole em situações de stress". 0 aluno F9 relata: "Para mim, os valores foram o autoconhecimento, aliado ao comprometimento pessoal, e a coragem de sair da zona de conforto".

Nas respostas dos educadores da instituição, também encontramos diversas menções a esses temas, sendo que oito dos doze instrutores referiram-se a eles, utilizando expressões como superação de medos e desafios, vencer desafios e coragem, assim como outras que remetem a tais questões, como "aprendem a confiar mais em si mesmos" (I7), "descobrir que podem muito mais do que imaginam alcançar" (I8), ou, ainda, "autoconfiança (acreditar em si mesmo conhecendo melhor o seu potencial de ação)" (I10). A instrutora I12 trata da multiplicidade e da diversidade de desafios. Segundo ela, há os desafios físicos, os técnicos, os exigidos pela vida ao ar livre e os de relacionamento entre as pessoas. Assim, algum desses aspectos sempre desafiará o participante, exigindo superação, esforço pessoal, disciplina e coragem.

Associados à coragem e ao esforço pessoal, identificamos elementos de legitimação ou de busca por autorrespeito, conforme tratado por Le Breton (2009). Ressaltamos aqui a importância da experiência concreta, com destaque para a representação que a natureza tem no imaginário das pessoas como lugar de desafio e superação.

Outra inferência em relação à experiência de superação e valorização da virtude da coragem está no papel do educador em ajudar seu aluno a compreender que, para algumas virtudes, não há medida exagerada. Como exemplo, lembramos que não é possível uma pessoa ser demasiadamente honesta ou íntegra. Para a virtude da coragem, contudo, o excesso pode não ser a melhor medida. Se, por um lado, pouca coragem caracteriza covardia e inação, o exagero pode significar estupidez, temeridade, e trazer consequências indesejadas. A sabedoria repousa em algum lugar entre esses limites.

É importante que instrutores de educação pela aventura, possivelmente vistos como destemidos e capazes aos olhos de seus alunos, saibam aceitar alguns desafios e declinar de outros, pois assim estarão, por meio do exemplo, oferecendo uma lição importante aos seus alunos.

\section{Autoconhecimento}

Outro aspecto decorrente das experiências vividas nos cursos de educação ao ar livre, segundo relatos dos alunos adolescentes, dos alunos adultos e dos educadores, está na oportunidade de adquirir conhecimento sobre si mesmo. As experiências que abordam disciplina, esforço, superação e coragem também permitem que a pessoa se conheça melhor. Além das menções diretas ao autoconhecimento, obtivemos relatos sobre o reconhecimento dos próprios limites e sobre a autopercepção dos pontos fracos e fortes. 
La Taille (1998) trata de duas dimensões do termo limite que estão diretamente relacionadas ao autoconhecimento e que se aplicam às experiências e aos aprendizados de cursos de educação ao ar livre. A primeira delas refere-se aos limites que devem ser superados, seja pelo amadurecimento biológico de uma criança, seja pela busca da excelência. Quando um aluno relata que o curso o fez perceber que é mais capaz, resistente ou tolerante do que imaginava ser, entendemos que ele viveu uma experiência que lhe permitiu conhecer-se melhor e perceber que pode ir além do que suponha. É a esse tipo de limite que o aluno A3 refere-se ao dizer: "Nossa, consegui chegar aqui. Uma sensação de ter conseguido".

A segunda abordagem do termo diz respeito à barreira que não deve ser transposta, seja por uma questão de respeito ao próximo, seja pelo respeito a si mesmo. 0 limite além do qual se pode desrespeitar ou ferir alguém ou a si mesmo deve ser identificado e aceito. É a esse limite que se referem os instrutores I8 e I9 quando dizem, respectivamente: "acho que aceitar seus limites, reconhecer os seus valores" e "conhecer alguns de seus limites físicos e psicológicos".

Porém, como uma pessoa aprende quais limites deve transpor e quais deve respeitar? Entendemos que a experiência seguida do pensamento reflexivo pode prover tal aprendizado.

Ao tratarmos do autoconhecimento pela abordagem dos limites, não nos referimos apenas aos conhecimentos sobre quão longe se deve ir, quanto se deve arriscar ou quanto se deve expor-se em cada tipo de experiência, mas também ao desenvolvimento moral de quem se depara com tais questões. Como nos ensina La Taille (1998), não há alto padrão ético sem a busca pela excelência, ou seja, pela superação de limites. Da mesma forma, não há moralidade aceitável sem o respeito ao outro ou a si mesmo. Os questionamentos sobre as formas éticas de como agir decorrem das experiências que levam as pessoas à superação de seus limites, e, para tal, a intervenção do educador faz-se fundamental.

\section{Situações de conflito, respeito e a intervenção do educador}

Nas entrevistas, chamam atenção as situações de desentendimento ou conflito que levam ao desrespeito e à radicalização de posições antagônicas que, em vez de centradas em alguma tarefa ou postura filosófica, agridem a pessoa, sobretudo entre os alunos mais jovens.

Questões simples, como quem deve lavar a louça ou ir buscar água, e brincadeiras em momento de cansaço geram brigas, xingamentos e desrespeitos típicos de jovens que ainda não dominam suas emoções ou a forma como se expressam. A experiência de múltiplos dias na natureza coloca-os diante da impossibilidade de irem imediatamente para suas casas após o entrevero e até de afastarem-se longamente de seus desafetos, obrigando-os a conviver, buscar o diálogo e tentar encontrar soluções.

Vejamos alguns exemplos de conflitos que geraram desrespeito entre os jovens e as soluções encontradas. 0 aluno A1 relata a seguinte situação:

Você já andou o dia inteiro mais de dez quilômetros, você está com a mochila... Vamos dizer que são oito quilos de mochila, mas nas suas costas dá uns quinze, cara. É muito pesada a mochila. Você tem que chegar, às vezes, de noite no acampamento, montar o acampamento. E isso aí já vai acumulando estresse. A hora que explode... Aí, quando a gente tem que puxar assim: a gente monta uma roda. Teve que fazer um negócio, pegar um pedaço de pau e falar: É microfone. Só fala quem tiver isso na mão. Porque, senão, todo mundo fala um por cima do outro. É ruim. A mesma coisa das funções; tem as funções: limpeza, hidratação. Nossa, isso aí era o que mais causava discussão.

0 aluno A3 recorda:

Me chamaram para fazer isso, que não era nem a minha função. Aí, eu fiquei muito 
bravo. Aí, eu dobrei o negócio. Fiquei bravo, xinguei um monte de gente lá. Aí, depois eu me acalmei. Até fiquei dando risada lá. E eu me acalmei. Fiz o negócio, fiz de qualquer jeito, fiz de mau humor. Mas, aí, depois de uns cinco minutos, assim, eu me acalmei. Até pedi desculpa para o pessoal, porque eu xinguei todo mundo lá. Aí, eles até vieram falar que todo mundo se assustou, porque eu sempre sou alegre, não sei o quê. E eu fiquei muito bravo. É um tipo de coisa que me irrita muito: você me chamar, tirar... Eu estou lá, estava mó cansado e me tiraram de dentro da barraca. [...] Me chamar para resolver uma coisa que não é a minha função. E é uma coisa que você faz em um minuto: qualquer um faz. Eu fiquei bem irritado.

E são do aluno A5 as seguintes palavras:

Quando alguém queria, tipo, comer alguma coisa e o outro não queria, aí, eles acabavam brigando. $\mathrm{Ou}$ por bobeirinha mesmo, um xinga o outro e fica nessa, um fica xingando o outro para lá e para cá. Como resolve? Todo mundo conversa, aí eles resolvem.

Todavia, será que apenas o convívio é suficiente para o desenvolvimento dos alunos em suas capacidades de resolução de problemas, desviando-os da rota dos extremismos, do desrespeito, e conduzindo-os à compreensão? Cremos que a intervenção do educador é de extrema importância na maioria das situações. Depoimentos de alunos adolescentes, adultos e dos próprios instrutores conduzem-nos a essa inferência.

Nota-se, contudo, uma diferença interessante entre os alunos adolescentes e adultos. Se, entre os mais jovens, a intervenção do educador é fundamental para apaziguar os ânimos, evitar violência verbal e até física, organizar as falas dos ansiosos e auxiliar na construção de soluções, na atuação com alunos adultos, cabe ao educador expor os conflitos, abrir as feridas para permitir que questões subliminares ve- nham à tona e sejam solucionadas. 0 instrutor I9 relata um exemplo em que os alunos passaram quase a totalidade do curso evitando a exposição do que os incomodava e contornando os conflitos. Somente ao final, estimulados pelos instrutores, eles se abriram.

\section{Solidariedade, compaixão}

As respostas às entrevistas e aos questionários apresentaram, com bastante frequência, a compaixão expressa por atos de solidariedade. Dentre os nove alunos adolescentes entrevistados, quatro relataram a importância do cuidado com o outro na experiência vivida.

Tomamos como exemplo o aluno A8, que demonstrou solidariedade e compaixão ao dizer:

às vezes, a gente é muito individualista e a gente precisa desse tempo, dessa experiência, para poder conhecer pessoas e ver que o mundo não é feito de um cidadão só.

Do depoimento do aluno A1, extraímos a seguinte passagem:

aí que vem a união do grupo: “Não, vamos, vamos... A gente consegue e tal, todo mundo junto. É o que vai: um animando o outro. Porque se dependesse sozinho, você não consegue.

La Taille (1998) apresenta a afetividade como uma dimensão da educação elucidativa, identificada em pesquisa de Elliot Turiel ${ }^{1}$. Para esses autores, é o coração sensibilizado que fará os jovens optarem pelo certo e justo em vez do errado. Como já discutimos, agir moralmente requer a combinação entre razão e compaixão. Saber o que é justo não necessariamente levará à ação certa; contudo, tal saber aliado ao querer o que é certo poderá fazê-lo.

Seria utópico imaginarmos que os alunos vivem em clima de constante apoio mútuo e compaixão durante toda a experiência.

1- TURIEL, Elliot. The development of morality. (manuscrito). 
Evidentemente, esses momentos de solidariedade são entremeados com as típicas impaciências juvenis, e os relatos de conflito anteriormente analisados não deixam dúvidas em relação a isso. Entretanto, para os jovens que se encontram em situação desafiadora, a ocorrência de momentos de apoio mútuo parece ser significativa.

Para quem recebe o apoio em momentos de dificuldade, para quem o oferece e também para quem não está nem desconfortável e tampouco ofereceu qualquer ajuda ou conforto, parece haver motivos para reflexões. Tais reflexões serão mais profundas quanto mais hábil for a intervenção do educador, trazendo à luz e ao debate o tema do cuidado com o outro.

Entre os alunos adultos, a compaixão é um valor recorrente. A aluna F13 afirma ter sido "bastante acolhida pelo grupo". E são do aluno adulto F4 as seguintes palavras:

lembro do primeiro dia de caminhada depois da canoagem, em que alguns membros sentiram dificuldades para subir a serra e vários outros se dispuseram a dividir o peso da mochila dos que tinham maiores limitações físicas.

0 aluno F12 faz uma análise mais ampla da questão:

As relações humanas que são estabelecidas com base em respeito, empatia, compaixão e responsabilidade pelo outro e pelo ambiente educam para o saber ser e o saber conviver, que são bases para a formação de qualquer cidadão.

No total, oito dos dezessete alunos adultos fizeram menção à solidariedade, à compaixão ou ao cuidado em suas respostas.

Entre os educadores da escola, a solidariedade e o cuidado com o outro é o tema mais mencionado. Nove dos doze instrutores que responderam à pesquisa referiram-se a esse tema e demonstraram consciência de sua importância.

\section{Justiça}

Nota-se que os temas da solidariedade e da justiça ficam próximos um do outro. Redistribuir o peso das mochilas é uma questão de cuidado com o outro ou, primordialmente, de justiça? 0 aluno menos robusto não teria o direito de carregar menos peso? Há inúmeras situações que se encaminham para as discussões sobre justiça, solidariedade e a diferença entre igualdade e equidade. Nesses casos, a igualdade não representa a justiça, ou seja, o justo não é tratar todos de forma idêntica, mas de forma equânime, proporcional às suas limitações e potencialidades.

Um bom exemplo das questões referentes à justiça ao longo de um curso foi apresentado pelo aluno A8, que volta ao tema das tarefas, mas inclui um novo elemento:

Tem gente que não gosta, por exemplo, de lavar louça. E era muito chato, porque tinha gente que lavava, gente que não gostava, isso sempre gerava discussão. Então, o instrutor chegava e mostrava para a gente como fazer isso da maneira certa. E também, no caso das bolsas, tinha gente que não gostava de levar peso. Então, isso sempre gerava conflitos. E, por ter essa diferença social, às vezes, é um pouco complicado. [...] A gente sempre se unia na roda, conversava e cada um expressava sua opinião. E o instrutor sempre falava o jeito mais ou menos certo de como as coisas deveriam acontecer.

Além da questão das tarefas diárias e do debate sobre quem deveria ou não fazê-las, esse mesmo aluno faz menção a uma diferença social entre os participantes, com potencial para ricos debates e aprendizados. Ele refere-se ao fato de o grupo ser formado por pessoas de situação socioeconômica mais favorável e por bolsistas economicamente menos favorecidos. É evidente que a situação socioeconômica de 
cada participante não deve influenciar em nada as decisões e atribuições de tarefas ao longo do curso; em tal ambiente, todos são iguais e suas condições financeiras não compram conforto. Porém, para os adolescentes, parece ter havido algum mal-estar ou algum debate em relação à questão. Essa é uma situação em que o educador, atento, deve observar se a solução eticamente aceitável advém do grupo, ou se ele próprio deve intervir, facilitando a discussão. 0 aluno entrevistado não entrou em detalhes sobre como o educador atuou, mas deixou claro que houve a intervenção.

Parece-nos fundamental, na atuação do educador, pontuar a diferença entre solidariedade e justiça: não se trata de interpretar o justo como generoso, nem de necessariamente conceber o generoso como justo; tampouco se trata de achar que a lei é sempre sinônimo de justiça, ou que a virtude está na esperteza à margem da lei.

\section{Estudo de caso: o aluno do abrigo}

Dentre os nove alunos adolescentes entrevistados, havia um advindo de um abrigo para menores. Trata-se do aluno adolescente A4, que, por apresentar alterações comportamentais significativas logo após o término do curso, despertou interesse investigativo. Realizamos uma entrevista com a coordenadora e psicóloga do abrigo a partir da qual apresentamos algumas reflexões.

A coordenadora do abrigo descreve duas mudanças atitudinais mais relevantes no comportamento do jovem. A primeira refere-se à forma menos agressiva e mais respeitosa com que ele passou a tratar as pessoas ao seu redor; a segunda diz respeito ao fato de o jovem demonstrar mais iniciativa para realizar as tarefas necessárias ao início de sua vida profissional e à sua futura emancipação em relação ao abrigo. Ambas as mudanças, segundo a entrevistada, ocorreram exatamente após o regresso do curso que o jovem realizou.

Dado que as alterações de comportamento ocorreram exatamente após a experiência vivida pelo aluno, assumimos que o curso tenha tido influência em tais alterações. Contudo, concordamos com a análise da coordenadora do abrigo quando ela diz:

então, eu não sei se tem a ver um pouco, também, com a maturidade que está se aproximando um pouco desse momento e a ficha está caindo.

Provavelmente, as mudanças comportamentais do jovem devem-se também ao seu amadurecimento. Essa perspectiva está alinhada com Piaget (1998) e seus conceitos de equilibração e autorregulação, assim como com Dewey (1959) e seu conceito de interação.

$\mathrm{Na}$ trilogia entre experiências de vida, educação formal e maturidade biológica, o curso contribuiu com experiências que fizeram o jovem alterar seu comportamento. Contudo, quais seriam essas experiências? Aqui, entramos no terreno das suposições.

Assumimos a possibilidade de o simples distanciamento da realidade do dia a dia do jovem ter contribuído para sua reflexão. A possibilidade de viver experiências diferentes das cotidianas, em local também distinto e sob o estímulo da reflexão e das transferências de aprendizado, as quais são papel precípuo dos educadores ao ar livre, estimula o pensar sobre a realidade e a vida das pessoas. Portanto, pode ter havido contribuição gerada por esse distanciamento.

Outra possibilidade para entendermos as transformações ocorridas está na atribuição de tarefas e responsabilidades concretas aos alunos do curso. Possivelmente, podemos caracterizar o aluno A4 segundo o que Dewey (1959) entende como um jovem alienado pela ênfase na racionalização da escola. Em vez das típicas questões teóricas das salas de aula, aos alunos de um curso que se dá como uma expedição na natureza, atribuem-se tarefas concretas, como montar barracas, buscar água, cozinhar, achar os caminhos, entre outras.

De acordo com a coordenadora do abrigo, o aluno conta que cozinhava no curso. Ela 
também relata: "para outros, ele contou da experiência de que, sobre tudo, na verdade, eles eram instruídos, mas eles que tinham que fazer". Ao ser responsabilizado pela tarefa, duas possíveis consequências podem ser esperadas. A primeira é que, ter vivido as dificuldades de cozinhar o próprio alimento, o jovem passa a respeitar mais quem desempenha essa tarefa diariamente. É interessante notar que a atribuição de respeito às outras pessoas deu-se pela experimentação das tarefas por elas realizadas e pela atribuição de respeito a si próprio, por intermédio das mesmas tarefas.

A segunda possivel consequência advinda da responsabilização por tarefas está no ganho de confiança, e aqui frisamos a importância de uma educação voltada para o sucesso. Ao se sentir bem-sucedido com as responsabilidades que lhe foram atribuídas, o aluno percebe-se capaz e passa a gostar de atribuições e desafios. A coordenadora do abrigo relata os dizeres do aluno A4 e comenta:

Ele reconheceu que ele pode. Então, ele foi correr atrás das coisas. Ele falou: "Não...." Eu lembro que, uma vez, ele foi fazer a carteira e, aí, ele não chegou no horário. E, aí, não deu certo a carteira, mas ele falou: "Não, eu vou resolver sozinho. Eu não preciso do abrigo. Eu consigo ir sozinho, eu posso ir sozinho". Então, eu acho que a autoestima dele também melhorou bastante. E a autoconfiança de: "Não, eu posso, eu vou".

Acreditamos que o acréscimo de confiança em si próprio é um passo fundamental à capacidade de tomada de iniciativa. Relembramos que Piaget (1998) relaciona a iniciativa como um elemento importante ao desenvolvimento da razão e da moralidade.

Além da responsabilização pelas tarefas ao longo da expedição, podemos pressupor que, para o aluno A4, o convívio com os outros em um ambiente em que a solidariedade é necessária tenha causado algum impacto. 0 próprio aluno declara:

\begin{abstract}
Aí, tipo, um cansava, todo o grupo parava. Tipo, um quebrava a perna, todo o grupo estava ali, esperando. Não importava se ia chegar no acampamento à noite ou não. [...] Se uma pessoa estiver com a bolsa muito pesada, nós dividia o que tem na bolsa dela, para ficar mais leve para ela.
\end{abstract}

Como entender que o aluno tenha se sensibilizado para situações que requerem solidariedade numa expedição na natureza se o jovem, muito provavelmente, também vivencia situações que demandam tais comportamentos no abrigo em que vive? Uma das possibilidades para o entendimento dessa questão está no fato de que o jovem encontrou, no ambiente do curso, um valor socialmente aceito e valorizado para sua força física. Ou seja, sua condição física tornou-se uma ferramenta para o sucesso e o auxílio aos outros, principalmente por meio da espera pelos outros e da oferta para carregar mais peso.

No contexto da vida no abrigo, sua privilegiada condição física pode ser inútil ou mesmo um elemento de coerção entre os pares, ainda que de forma subliminar e não exercida de fato. Tal situação não o valoriza perante a instituição e os outros abrigados, conduzindo-o ao caminho da agressividade e da intimidação. Ora, se essa característica do jovem dificilmente pode ser valorizada em seu cotidiano, o que lhe resta como ferramentas para a autorrealização e o sucesso?

\section{Conclusão}

Esta primeira pesquisa sobre a educação ao ar livre no Brasil, nos moldes aqui delimitados, permite algumas inferências e sugere futuras investigações.

A partir do estudo de teóricos como Piaget (1994, 1998) e Dewey (1959, 1979), não há dúvidas de que a educação que ocorre por meio de vivências práticas e experiências concretas desperta maior interesse em alunos jovens ou adultos do que a que surge longe de suas realidades. 
Com base nesses mesmos teóricos e em seus seguidores, fica evidente a importância da experiência no desenvolvimento moral dos jovens. Contudo, para que se atinjam níveis éticos mais altos ou a possibilidade de autonomia nos julgamentos morais, faz-se fundamental a relação equânime e não coercitiva entre educadores e educando, especialmente entre os pares, com oportunidades de livre interação entre estes.

A educação ao ar livre provê múltiplas oportunidades de tarefas cooperativas entre seus alunos. Ela também lhes proporciona experiências significativas, pois a dinâmica de seus cursos demanda não apenas o julgamento moral dos dilemas que ocorrem, mas também as ações decorrentes da necessidade de resolução de problemas. Tais ações requerem iniciativa, a qual, conjuntamente com o esforço pessoal e a disciplina, é fundamental na realização de trabalhos em grupo.

A análise dos dados permite-nos afırmar que a educação ao ar livre aufere amplas oportunidades para que os alunos enfrentem situações que requerem a superação de limites físicos e emocionais, assim como a reflexão sobre os limites a serem transpostos e os que devem ser respeitados.

As teorias que tratam da moralidade apontam a justiça e a solidariedade entre seus valores fundamentais. $\mathrm{Na}$ análise dos dados, encontramos relatos sobre situações de solidariedade ou cuidado entre as pessoas, assim como de debates e conflitos que remetem a essas questões. Portanto, também sob esta ótica, os cursos de educação ao ar livre demonstram potencialidade para o desenvolvimento da moralidade dos alunos.

Entendemos, ainda, que os potenciais pedagógicos encontrados na proposta da educação ao ar livre ficam condicionados à existência de uma equipe de educadores preparada para lidar com as questões que tratamos ao longo deste estudo.

Na medida em que a vida nos grandes centros urbanos, por diferentes razões, restringe o acesso do jovem às áreas naturais, a educação pela experiência que se dá em tais locais ganha relevância para o desenvolvimento holístico de indivíduos atentos às questões éticas. 


\section{Referências}

BRASIL. Ministério da Educação e do Desporto. Secretaria de Educação Fundamental. Parâmetros Curriculares Nacionais: terceiro e quarto ciclos: apresentação dos temas transversais. Brasília, DF: MEC/SEF, 1998.

BRUHNS, Heloisa Turini. Esporte e natureza: 0 aprendizado da experimentação. In: SERRANO, Célia (Org.). A educação pelas pedras. São Paulo: Chronos, 2000. p. 25-46.

DEWEY, John. Democracia e educação. Tradução de Godofredo Rangel e Anísio Teixeira. São Paulo: Editora Nacional, 1959. (Col. Atualidades Pedagógicas, v. 21)

Experiência e educação. Tradução de Anísio Teixeira. 3. ed. São Paulo: Editora Nacional, 1979. (Col. Atualidades Pedagógicas, v. 131)

FORD, Phyllis M. Principles and practices of outdoor/environmental education. New York: John Wiley and Sons, 1981.

GARVEY, Daniel. Outdoor adventure programming and moral development. In: MILES, John C.; PRIEST, Simon. Adventure programming. Pennsylvania: Venture, 1999. p. 133-139.

LA TAILLE, Yves de. Limites: três dimensões educacionais. São Paulo: Ática, 1998.

Moral e ética: dimensões intelectuais e afetivas. Porto Alegre: Artmed, 2006.

LE BRETON, David. Condutas de risco: dos jogos de morte ao jogo de viver. Campinas: Autores Associados, 2009.

LIDDLE, Jeff. Risk management: walking the tightrope. The Journal of Experiential Education, v. 2, n. 2, p. 61-62, 1998.

MARINHO, Alcyane. Lazer, aventura e risco: reflexões sobre atividades realizadas na natureza. Movimento, Porto Alegre, v. 14, n. 2, p. 181-206, 2008.

MARTIN, Andrew John. Towards the next generation of experiential education programms: a case study of Outward Bound. Tese (Doutorado em Management) - College of Business, Massey University, Palmerston North, Nova Zelândia, 2001.

MENIN, Maria S. de Stefano. Desenvolvimento moral. In: MACEDO, Lino de. Cinco estudos de educação moral. São Paulo: Casa do Psicólogo, 1996. p. 37-104.

PIAGET, Jean. 0 juízo moral na criança. São Paulo: Summus Editorial, 1994.

. Observações psicológicas sobre o trabalho em grupo. In: PARRAT, Silvia; TRYPHON, Anastásia (Orgs.). Sobre a pedagogia: textos inéditos. São Paulo: Casa do Psicólogo, 1998. p. 137-151.

TRIVIÑOS, Augusto N. Silva. Introdução à pesquisa em ciências sociais: a pesquisa qualitativa em educação. São Paulo: Atlas, 1987.

Enviado em: 21.03.2011

Aprovado em: 13.10.2011

Flavio Theodor Kunreuther é mestre em Educação Física pela Escola de Educação Física e Esporte da Universidade de São Paulo e possui vasta experiência em educação por meio de atividades de aventura ao ar livre.

Osvaldo Luiz Ferraz é doutor em Educação pela Faculdade de Educação da Universidade de São Paulo e professor do curso de licenciatura em Educação Física e do Programa de Pós-Graduação (área de Pedagogia do Movimento Humano) da Escola de Educação Física e Esporte da Universidade de São Paulo. E-mail: olferraz@usp.br. 